\title{
O FINLANDÊS E O HÚNGARO E A TIPOLOGIA DA HARMONIA E DA DESARMONIA VOCÁLICA
}

\author{
Finnish and Hungarian: the typology of \\ vocalic harmony and disharmony
}

\section{Paulo Chagas de Souza ${ }^{* *}$}

\section{Introdução}

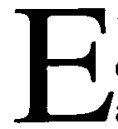

ntre os fenômenos que envolvem a interação entre fonologia e morfologia dentro de sistemas lingüísticos específicos inclui-se a harmonia vocálica, a qual já foi tema de uma grande quantidade de trabalhos, por apresentar uma mistura intrigante de características universais e características próprias de cada língua. Autores como Goldsmith (1985) e Archangeli e Pulleyblank (1994) trataram da harmonia vocálica. Uma discussão detalhada das principais questōes envolvidas é a que se encontra em van der Hulst e van de Weijer (1995). Com relação ao português, trabalhos como Bisol (1981; 1984; 1988), Harris (1974), Mateus (1975), Quicoli (1990) e Wetzels (1991) trataram desse tema.

Nas línguas com harmonia vocálica, certas combinações de vogais são admissíveis e outras não em domínios específicos. Krämer $(2001$, p. 3) define a harmonia vocálica como "the phenomenon where potentially all vowels in adjacent moras or syllables within a domain... systematically agree with each other with regard to one or more articulatory features." Essa é a definição que será utilizada neste artigo. Assim, sempre que duas sílabas adjacentes apresentarem concordância relativa ao traço pertinente, consideraremos que há harmonia vocálica, ao passo que sempre que elas não concordarem com relação a esse traço falaremos de desarmonia vocálica. $O$ finlandês e o húngaro, que são

* Agradeço a Gisela Collischohn os comentários aposs minha apresentaçāo no IV Workshop de Linguística Formal da USP.

** USP/FSA. pcsouza@usp.br 
SOUZA, P. C. de. O finlandês e o húngaro e a tipologia...

examinados neste artigo, são línguas que apresentam harmonia vocálica de anterioridade/posterioridade, também chamada harmonia palatal.

$\mathrm{Na}$ teoria fonológica, a pesquisa a respeito da harmonia vocálica tem focalizado predominantemente seu aspecto sintagmático, isto é, quais vogais podem coocorrer numa palavra, quais domínios são privilegiados sintagmaticamente (a sílaba inicial, a sílaba tônica, a raiz, etc.), pouco ou nada considerando de seu lado paradigmático. É o que se encontra em trabalhos como Goldsmith (1985), van der Hulst e van de Weijer (1995), entre outros, que são estritamente sintagmáticos.

Também dentro da Teoria da Otimidade (doravante TO), o quadro teórico que será utilizado neste artigo, os trabalhos majoritariamente analisam apenas o lado sintagmático da harmonia vocálica. Krämer (2001) e Kiparsky e Pajusalu (2003) apresentam análises estritamente sintagmáticas. Este último tangencia o lado sintagmático, mas sem tocá-lo realmente. Podem-se ainda, no entanto, considerar trabalhos como o de Bakovi (2000), que analisa principalmente a relação entre a raiz e os afixos de uma determinada forma, o que tem reflexos paradigmáticos.

Os trabalhos que já trataram especificamente do funcionamento dos paradigmas na TO incluem Benua (1997), Burzio (1998) e McCarthy (2002b). Benua tratou de situações em que uma palavra morfologicamente derivada, ao contrário do que seria de se esperar por sua forma superficial, apresenta coincidência com a forma de sua base, num caso de superaplicação ou subaplicação. Burzio trata de derivações morfológicas a partir de duas bases, ou seja, derivações de um item lexical não composto que apresenta características deriváveis de duas outras formas vocabulares (por ex., o substantivo vincitore em italiano apresenta o sufixo -ore, que normalmente é afixado ao tema do particípio passado, mas nesse caso é afixado ao tema do infinitivo). McCarthy discute os fenômenos de abreviação e epêntese vocálicos no árabe clássico como resultado da atuação de um tipo de restrição que privilegia os paradigmas nivelados, ou seja, sem alternância.

O objetivo deste trabalho é começar a examinar esse lado pouco explorado da harmonia vocálica, seu comportamento paradigmático, por meio da investigação do seu funcionamento em húngaro e em finlandês, numa perspectiva compatível com a da TO. Neste artigo, apresentam-se as diferenças no comportamento paradigmático da harmonia e da desarmonia vocálica em finlandês e em húngaro, que se mostrarão claras e bem marcadas. Se essas diferenças paradigmáticas detectadas serão mais bem explicadas como resultado de restrições especificamente paradigmáticas ou apenas como reflexos de restrições sintagmáticas é algo que pesquisas posteriores poderão esclarecer. 
SOUZA, P. C. de. O finlandês e o húngaro e a tipologia...

\section{O núcleo comum}

Como já foi dito, o finlandês e o húngaro são dois exemplos comuns de línguas que apresentam harmonia vocálica do tipo anterior/posterior. $\mathrm{O}$ foco deste trabalho será o finlandês $(F)$. O húngaro $(\mathrm{H})$ será aqui empregado como termo de comparação. O inventário vocálico das duas línguas é o que se encontra nas tabelas a seguir:

TABELA 1 - VOGAIS DO FINLANDÊS ${ }^{1}$

\begin{tabular}{|c|c|c|c|c|}
\hline- arred & + arred & - arred & + arred & \\
\hline $\mathbf{i}$ & $y$ & & $\mathrm{u}$ & + alto - baixo \\
\hline c & $\sigma(\ddot{\theta})$ & & 0 & - alto - baixo \\
\hline $\mathfrak{x}(\mathrm{a})$ & & $A$ & & - alto + baixo \\
\hline \multicolumn{2}{|c|}{ - post } & \multicolumn{2}{|c|}{+ post } & \\
\hline
\end{tabular}

TABELA 2 - VOGAIS DO HÚNGARO²

\begin{tabular}{|c|c|c|c|c|}
\hline- arred & + arred & - arred & + arred & \\
\hline$i$ il & y (ï) y & & u $u\rceil$ & + alto - baixo \\
\hline $\mathrm{c}$ & $O(\ddot{0}) O\rceil(\tilde{0})$ & & $\begin{array}{ll}0 & 0\end{array}$ & - alto - baixo \\
\hline $\mathrm{E}$ & & A a & & - alto + baixo \\
\hline \multicolumn{2}{|c|}{- post } & \multicolumn{2}{|c|}{+ post } & \\
\hline
\end{tabular}

1 Todas essas vogais podem ser breves ou longas.

2 Diferentemente de Kràmer (2001), trato o a breve como uma vogal não-arredondada, o que está mais de acordo com fontes húngaras como Bánhidi et al. (1965). 
SOUZA, P. C. de. O finlandes e o húngaro e a tipologia...

Em ambas as línguas é o traço [ \pm Posterior] que está envolvido na harmonia vocálica, ou seja, todas as vogais devem apresentar valor idêntico com relação a esse traço. Pode-se também considerar que há uma subdivisão do inventário vocálico em vogais com ponto coronal e com ponto dorsal (cf. Clements; Hume, 1995). Exemplos: ${ }^{3}$

1) apenas vogais posteriores (H): áru 'mercadoria', távol 'distante'

2) apenas vogais anteriores (H): mise 'missa', röpcsi 'avião', csütörtök 'terça-feira'

3) apenas vogais posteriores (F): talo 'casa', apu 'ajuda', tulo 'chegada'

4) apenas vogais anteriores (F): eläin 'animal', tyttö 'menina', pöytä 'mesa'

São impossíveis palavras com combinações de vogais anteriores e posteriores $(F)^{4}$ :

5) * talö, * tälo, * apy, * äpu, * tytto, * tuttö, * pöyta, * poutä

Ambas as línguas têm como padrão geral a harmonia vocálica controlada pelo radical (Bakovi, 2000), o que, aliado ao fato de ambas terem flexão no final da palavra, produz o que se poderia descrever como harmonia da esquerda para a direita. Seguem alguns exemplos que demonstram como o radical (ou raiz, se ela for livre) determina a forma dos afixos flexionais:
6) hús 'carne' e húsból 'de (dentro da) carne'
7) tüz 'fogo' e tüźól 'de (dentro do) fogo'
8) tuo 'aquele' e tuolla, 'lá (lit. naquilo)'
9) työ 'trabalho' e työllä 'no trabalho'

3 Utiliza-se nos exemplos a grafia oficial das duas línguas. Deve ser observado que elas diferem na forma de transcrever a quantidade vocálica. Em finlandès, as vogais longas são escritas dobradas (exs.: suu 'boca' e maa 'país'). Já em húngaro, as vogais longas recebem o acento agudo (exs.: már 'já' e viz 'água') ou duplo acento agudo, e quando breves sāo grafadas com trema (cp. fiil, "orelha', com [y] breve, e e fii, 'grama', com [y] longo). Outro detalhe: em ambas as línguas, o acento primário incide sempre sobre a sílaba inicial.

4 Essa generalização se refere a formas nativas ou há muito incorporadas ao léxico finlandês. Empréstimos cultos, como os de origem greco-latina, frequentemente apresentam desarmonia, em consonância com sua forma original. Ex.: analyysi 'análise'. Uma parcela dos falantes tende a fazer análises morfológicas baseadas na harmonia vocálica, obtendo [ana] e [lyysi], as quais podem coincidir a estrutura morfológica na língua de origem do empréstimo, como nesse caso, ou não. 
SOUZA, P. C. de. O finlandés e o húngaro e a tipologia...

O primeiro par em cada língua apresenta palavras que contêm apenas vogais posteriores, enquanto o segundo par apresenta palavras que contêm apenas vogais anteriores. $O$ crucial é que é a raiz, a qual não alterna entre duas realizações (com vogal anterior ou posterior), é que determina qual dos alomorfes de cada sufixo será empregado.

Um fator complicador que se verifica em diversas línguas que apresentam harmonia vocálica, inclusive o finlandês e o húngaro, é o fato de essas línguas terem as chamadas vogais neutras. Normalmente são vogais que não possuem vogal correspondente no subconjunto de vogais complementar. No caso do húngaro e do finlandês, são vogais foneticamente anteriores que não têm correspondentes posteriores. Em consequiência disso, elas podem coocorrer tanto com vogais anteriores quanto com vogais posteriores. Dessa forma, têmse exemplos como o finlandês kone 'máquina', mehu 'suco', lintu 'pássaro' e tuuli 'vento', bem como exemplos como o húngaro mozi 'cinema', fiú 'menino/ rapaz' e béka 'sapo'.

Dentro da caracterização tradicionalmente sintagmática dos sistemas de harmonia vocálica, uma distinção normalmente feita é a que existe entre os dois padrões normalmente atestados nas línguas naturais quando há uma vogal nãoneutra na margem a partir da qual se propaga a harmonia vocálica, se essa vogal não-neutra é seguida por uma sílaba com vogal neutra na sílaba adjacente a ela. A vogal neutra pode iniciar um novo domínio harmônico, caso em que se diz que essa vogal é opaca; ou então a harmonia vocálica pode como que "passar por cima" da vogal neutra, caso em que se diz que essa vogal é transparente.

Ambas as línguas ( $\mathrm{F} \mathrm{e} \mathrm{H}$ ) apresentam o mesmo comportamento se considerarmos que suas vogais neutras são transparentes. Assim, dado um radical que contém uma vogal posterior na primeira sílaba e uma vogal neutra na segunda sílaba, um sufixo que apresente alomorfia harmônica e que forme a terceira sílaba da palavra apresentará o alomorfe com vogal posterior. É o que se pode verificar a partir de exemplos como tunti, tuntia, respectivamente nominativo e partitivo de 'hora' em finlandês, e Zsúzsi, Zsúzsival, respectivamente 'Suze' e 'com a Suze' em húngaro. Em ambas as palavras temos uma vogal posterior na primeira sílaba, uma vogal neutra (foneticamente anterior) na segunda sílaba, e novamente uma vogal posterior na terceira sílaba, que apresenta um sufixo flexional. ${ }^{5}$

Em suma, as características comuns entre a harmonia vocálica em húngaro e finlandês são as seguintes:

5 Ver mais detalhes em van der Hulst e van de Weijer (1995). 
SOUZA, P. C. de. O finlandês e o húngaro e a tipologia...

a) o traço envolvido é [ \pm posterior]

b) a especificação das raízes predomina sobre a dos afixos

c) o espraiamento se dá da esquerda para a direita (talvez se resuma a (b))

d) ambos possuem vogais anteriores não-arredondadas que são chamadas neutras por poderem coocorrer com vogais posteriores

e) as vogais neutras são transparentes

\section{Vogais neutras: não-neutralidade, harmonia e desarmonia}

Ao contrário do que a caracterização parcial feita até aqui do comportamento fonológico das chamadas vogais neutras poderia nos sugerir, elas estão longe de ser absolutamente neutras. A única característica que faz delas neutras é o fato de elas poderem coocorrer com vogais do subconjunto complementar no mesmo domínio harmônico. Há várias outras características, contudo, que indicam que elas têm um papel ativo na determinação de qual o valor do traço alternante, ou seja, seu papel não é neutro. As características dessa não-neutralidade são o primeiro ponto em que o húngaro e o finlandês diferem.

Em primeiro lugar, em finlandês, por exemplo, quando adjetivos e substantivos que têm somente [i] e [e] no radical ocorrem com algum sufixo flexional alternante, eles sempre apresentam apenas afixos flexionais com vogais anteriores. Exemplos:

10) viini e viiniä 'vinho' (nominativo e partitivo)

11) tie e tietä 'estrada, caminho' (nominativo e partitivo)

12) pieni e pientä 'pequeno' (nominativo e partitivo)

Além disso, os verbos com raizes que só contêm vogais neutras também se conjugam sempre com vogais anteriores, tendo, por ex., infinitivos em $-\ddot{a}$, e não em - $a$ :

13) tien e tiedä 'saber' (lpsg pres. indicativo e infinitivo)

14) menen e mennä 'ir' (lpsg pres. indicativo e infinitivo) 
SOUZA, P. C. de. O finlandês e o húngaro e a tipologia...

De maneira semelhante, em húngaro, a grande maioria ${ }^{6}$ das raízes que contêm apenas vogais anteriores desencadeia harmonia com vogais anteriores, como se vê nos seguintes exemplos de nominativos singulares e plurais:

15) viz, vizek 'água'

16) nép, népek 'povo'

17) mell, mellek 'seio'

18) cikk, cikkek 'artigo'

As semelhanças, no entanto, param por ai?. Ambas as línguas surpreendentemente preferem a desarmonia vocálica em certas situações. Os contextos e a forma dessa desarmonia distinguem as duas línguas. Ao lado das raízes neutras harmônicas, o húngaro tem raízes que contêm apenas vogais neutras, as quais são seguidas por sufixos flexionais com vogais posteriores, ou seja, nos termos de Krämer (2001), essas cerca de 100 raízes são "troianas", pois aparentam ser uma coisa (anteriores) e na realidade são outra (já que funcionam como posteriores). Exemplos:

19) hid, hidak 'ponte'

20) ir, irok 'escreve, escrevo'

Quais raízes com vogais neutras são harmônicas e quais são desarmônicas em húngaro é algo determinado lexicalmente. Assim, as exceções devem ser aprendidas. Não exploro em detalhes a questão dessas vogais troianas do húngaro, primeiro pelo fato de elas serem excepcionais dentro do húngaro; segundo pelo fato de a análise feita por Krämer (2001) necessitar de uma conjunção local ${ }^{8}$ de três restrições, algo a ser evitado, se possivel; e, finalmente, pelo fato de o húngaro ser utilizado neste artigo mais como termo de comparação, como já foi dito.

Quando são examinados os casos de desarmonia em finlandês, constatase que eles têm um caráter bem distinto dos do húngaro. Pode-se considerar a desarmonia em húngaro como algo determinado morfologicamente, já que certas raízes a impõem. Em finlandês, por outro lado, a desarmonia é determinada fonologicamente, pois ela ocorre, por exemplo, com certos sufixos derivacionais alternantes com relação ao traço [ \pm posterior] mas realizados sempre com vogais

6 Note-se que falo em húngaro da grande maioria das raízes, e não de todas. como no finlandès.

7 Até aqui, viu-se o que a literatura costuma apontar sobre a harmonia vocálica em F e $\mathrm{H}$. Passa-se agora a apresentar o que a literatura não discute.

8 Ver p. 87. 
SOUZA, P. C. de. O finlandês e o húngaro e a tipologia...

arredondadas. São sufixos como $-O k s^{9}$ (formador de nominalizações de verbos) e $-O$ (formador de substantivos e adjetivos). Quando acrescidos a raízes monossilábicas, eles são realizados com vogais posteriores, embora a raiz contenha apenas vogais anteriores. Exemplos:
21) mennä 'ir'
meno 'ida'
22) kiittää 'agradecer'
kiitos 'agradecimento'
23) elää 'viver'
elo 'vida'

Essa preferência pela desarmonia se verifica também em palavras monomorfêmicas.
24) eno 'tio'
25) mehu 'suco'
26) pelto 'campo, plantação'

Portanto, diferentemente do que ocorre em húngaro, em que a desarmonia é excepcional, em finlandês ela é sistemática nessas situações.

Voltando à questão da neutralidade, o importante, em suma, é observar que essas vogais não se comportam como absolutamente neutras quando estão na raiz, tendo na verdade dois tipos de comportamento fonológico: há uma clara preferência por vogais anteriores na maioria dos paradigmas flexionais em húngaro e na totalidade dos paradigmas flexionais em finlandês; de alguma forma, no entanto, essa preferência fica invertida nas situações apontadas em finlandês, ou seja, essas vogais preferem, ao contrário do que se esperaria, coocorrer com vogais posteriores.

Essa surpreendente preferência que as línguas com harmonia vocálica manifestam em certos contextos pela ausência de harmonia vocálica já havia sido o foco de Chagas de Souza (2002a, b), que focaliza o aspecto paradigmático da harmonia e da desarmonia vocálica. Kiparsky e Pajusalu ${ }^{10}$ (2003) também mencionam esse fato e buscam estabelecer o início de uma tipologia de desarmonia vocálica. Novamente, no entanto, como a análise destes também se restringe ao aspecto sintagmático da harmonia e desarmonia vocálica, o quadro fica limitado. Além disso, sua análise se limita às situações em que é possível ocorrer tanto harmonia quanto desarmonia, indiferentemente, não tratando das situações em que a desarmonia é preferida.

9 Realizado como -os ou - ఠs no nominativo, devido a restrições a codas complexas.

10 Para facilitar a leitura, a partir desta página, os autores Kiparsky e Pajusalu serão citados com a abreviatura $K$ e $P$. 
SOUZA, P. C. de. O finlandês e o húngaro e a tipologia...

Os fatos com relação ao finlandês são os seguintes: em primeiro lugar, com relação às vogais não-neutras, é preciso distinguir as vogais anteriores arredondadas (ö, ï) e vogal anterior baixa (ä), que não é arredondada. K e P aludem à possibilidade de que haja uma diferença entre esses dois subconjuntos, mas não exploram essa possibilidade. Na verdade, em nenhum momento a análise feita por eles considera essa diferença, tanto que a restrição por eles empregada é abreviada como $* \ddot{a}, *^{*} \ddot{o}, * \ddot{u}$.

Essa importante distinção entre [ä], de um lado, e /ö, ü/, de outro, se manifesta com radisais monossilábicos e dissilábicos. Como afirmam $\mathrm{K}$ e $\mathrm{P}$, após uma vogal neutra na primeira sílaba, tanto [a] quanto [ä] são possíveis no radical, como pode ser constatado pela grande quantidade de exemplos como sinä 'você', em que encontra-se [i...ä], e de exemplos como viitta 'casaco' em que encontrase [i...a]. Nesse mesmo contexto, contudo, há uma surpreendente preferência por [o, u] em detrimento de [ö, ü], de maneira que formas como eno 'tio' e mehu, 'suco', são extremamente mais comuns do que formas como levy 'disco' e niitty 'prado', que são extremamente raras.

Essa preferência é ortogonal a distinções como adjetivos vs. substantivos (por ex. iso 'grande', heikko 'fraco', e kirkko 'igreja', hermo 'nervo'), ou substantivos primitivos vs. nominalizações (pelto 'campo' e eno 'tio' vs. lento 'vôo' e pesu 'lavagem').

A generalização que pode ser feita é que tanto as raizes dissilábicas quanto os radicais dissilábicos compostos de raiz + sufixo, se contêm uma vogal neutra na primeira sílaba, apresentam uma preferência acentuada pela desarmonia e não pela harmonia.

Mesmo sem levar em consideração os paradigmas, pode-se constatar esse fato, que não foi ainda apontado claramente na literatura. $\mathrm{K}$ e $\mathrm{P}$ chegam a mencionar palavras como pesu 'lavagem' e tieto 'conhecimento', mas apenas para apontar que é possível a ocorrência de sufixos com vogal posterior arredondada na segunda sílaba, algo bem diferente de afirmar que existe na verdade uma preferência por esse tipo de sequiência desarmônica de vogais.

Apresenta-se a seguir a hierarquia de restrições proposta por $\mathrm{K}$ e $\mathrm{P}$ para explicar o funcionamento da harmonia e da desarmonia em finlandês. Sua aplicação se revela inadequada para o caso discutido aqui, no qual há um [e] na primeira sílaba e um [o] ou [ö] na segunda sílaba. Adotou-se a prática de explicar o caso mais difícil, ou seja, como a sequiência [e...ö], possível no input, acaba sendo realizada como [e...o]. 
SOUZA, P. C. de. O finlandês e o húngaro e a tipologia...

TABLEAU 1 - HIERARQUIA DE K E P COM VOGAIS ARREDONDADAS NA SEGUNDA SÍLABA ${ }^{11.12}$

\begin{tabular}{|c|c|c|c|c|}
\hline /c...ö/ & MH & $\begin{array}{l}\text { ID-F,(BK) \& } \\
\text { ID-RT(BK) }\end{array}$ & $\mathrm{AGR}(\mathrm{BK})$ & ${ }^{*} \ddot{\mathrm{a}},{ }^{*} \mathrm{ö},{ }^{*} \mathrm{y}$ \\
\hline$*[c \ldots o]$ & & $* !$ & * & \\
\hline$\sigma[c . . . \ddot{0}]$ & & & & * \\
\hline
\end{tabular}

Examinemos melhor o tableau acima. Duas de suas restrições são restrições simples: AGr[BK], que penaliza cada transição entre vogais com desarmonia de posteridade; $e^{*} \ddot{a}, *_{0}, * y$, abreviatura que $\mathrm{K}$ e $\mathrm{P}$ utilizam para a restrição $[-B K] \Rightarrow[-L O,-R D]$, que penaliza a ocorrência de vogais anteriores que sejam baixas ou arredondadas.

As duas primeiras colunas apresentam conjunções locais (Smolensky, 1993) de duas restrições, isto é, uma restrição composta que só é violada caso as suas duas componentes sejam violadas localmente (no mesmo segmento, na mesma sílaba, etc.). A primeira conjunção local utilizada por eles é $\mathrm{MH}$, ou marked harmony, que só é violada caso haja um segmento desarmônico e um segmento marcado no mesmo domínio. ${ }^{13}$ A segunda conjunção local é ID-F $\mathrm{RT}(\mathrm{BK})$, violada quando houver um segmento no pé inicial ${ }^{14}$ ( $\mathrm{F}_{1}$ abrevia first foot) da raiz (RT, abreviatura de root). $\mathrm{O}$ conectivo \& indica a conjunção.

No tableau acima, MH não desempenha nenhum papel porque nenhum dos candidatos considerados a viola, já que [e...o] apresenta desarmonia mas não vogais marcadas, e [e...ö] apresenta a vogal marcada [ö], mas não desarmonia.

As outras três restrições hierarquizadas da forma como estão representam um problema, pois o candidato selecionado (indicado pelo símbolo $\sigma$ ) não é o que corresponde ao output real (indicado pelo símbolo $*$ ). Isso ocorre porque o

$11 \mathrm{~K}$ e P distinguem dois tipos de harmonia de marcaçāo (core markedhess hamony e generalized markedhess harmony). Como isso não terá nenhum efeito nos casos que estão sendo considerados e essas restrições são adjacentes na hierarquia deles, estus são apresentadas fundidas numa só, MH (markedness hamony).

12 A principal restrição da hierarquia de Kiparsky e Pajusalu é a ID-sl(Bk), que age no sentido de preservar o valor do traço [Dposterior] na primeira sílaba da palavra. Como ela nunca é violada em finlandess, foi omitida da hierarquia para simplificar a visualização.

13 Há, na verdade, duas restriçōes desse tipo em $\mathrm{Ke} \mathrm{P}$ (2003). A primeira delas (GENERALIZED $M H)$ evita a ocorrência de uma vogal marcada e uma vogal desarmônica no mesmo domínio, independentemente de elas serem a mesma ou não. A segunda delas (CORE $M H$ ) evita que a mesma vogal seja ao mesmo tempo marcada e desarmônica. A distinção entre elas só se revela em palavras com pelo menos três sílabas, o que exclui todos os exemplos considerados neste texto. Por isso, fundem-se as duas, adjacentes na hierarquia de $K$ e P, numa só aqui, para facilitar a exposição e a visualização.

14 O pé inicial compreende as duas primeiras sílabas da palavra, já que o acento primário sempre incide sobre a sílaba inicial. 
output real viola duas restrições - tanto $\mathrm{ID}_{-} \mathrm{F}_{1}(\mathrm{BK})$ \& ID-RT(BK) quanto AGR(BK) - que dominam a única restrição violada pelo candidato erroneamente selecionado - *ä, *ö, *y. Esse é um problema não apontado na literatura para o qual será postulada uma solução aqui. Essa solução é o desmembramento da restrição *ä, $*_{\ddot{o}}$, *y em duas: a restrição *ä, que penaliza ocorrências de vogais anteriores baixas, mantém sua posição baixa na hierarquia, mas a restrição *ö, *y, que penaliza ocorrências de vogais anteriores arredondadas, deve ocupar uma posição superior na hierarquia, o suficiente para dominar as restrições violadas pelo candidato que deve ser eliminado. A nova hierarquia está demonstrada no tableau a seguir.

TABLEAU 2 - HIERARQUIA PARCIAL AQUI POSTULADA ${ }^{15}$

\begin{tabular}{|c|c|c|c|c|c|}
\hline$/$ e....̈/ & $\mathrm{MH}$ & ${ }^{*} \ddot{0},{ }^{*} y$ & $\begin{array}{l}\text { ID-F/(BK) \& } \\
\text { ID-RT(BK) }\end{array}$ & $\operatorname{AGR}(\mathrm{BK})$ & $* \ddot{a}$ \\
\hline$\sigma[\mathrm{e} \ldots \mathrm{o}]$ & & & * & * & \\
\hline$[\mathrm{e} \ldots . .0]$ & & *! & & & \\
\hline
\end{tabular}

Essa nova hierarquia seleciona corretamente o candidato com a sequiência [e...o].

\section{Harmonia e desarmonia vocálica nos paradigmas}

Na página 78 , viu-se um conjunto de características comuns entre a harmonia vocálica em finlandês e em húngaro. A seguir, começaram-se a observar distinções entre as duas línguas. Se, ao contrário do que normalmente ocorre, forem considerados também os paradigmas flexionais e derivacionais, perceberse-á que há diferenças mais significativas por trás da aparente uniformidade. Examinemos os paradigmas, verificando primeiramente mais uma semelhança entre as duas línguas, seguida de algumas diferenças significativas.

A semelhança entre as duas línguas que deve ser apontada não recebe destaque dentro de uma análise sintagmática: o fato de, como se pode ver nas tabelas 1 e 2 do apêndice, ambas as línguas apresentarem paradigmas flexionais

15 Esta hierarquia parcial é a mesma utilizada em Nascimento (2003). A análise deste trabalho difere da de Nascimento em não considerar que essa diferença esteja associada a duas co-fonologias presentes no finlandês (uma associada aos verbos e outra aos adjetivos e substantivos), mas que é provavelmente o resultado da atuaçĩo de restrições paradigmáticas. 
SOUZA, P. C. de. O finlandès e o húngaro e a tipologia...

em que os sufixos são uniformemente harmônicos (rész em $\mathrm{H}$ e lähtö em F) ou uniformemente desarmônicos (híd em $\mathrm{H}$ e elo em F). ${ }^{16}$

Esses paradigmas são ambos nominais, mas com a distinção de que os sufixos desarmônicos são flexionais em húngaro e derivacionais em finlandês.

A primeira diferença se verifica nos paradigmas verbais. Os paradigmas flexionais verbais em húngaro apresentam as mesmas duas possibilidades apontadas acima para os substantivos, isto é, podem ser uniformemente harmônicos ou uniformemente desarmônicos. Essas duas possibilidades estão ilustradas na tabela 3 do apêndice, respectivamente com os verbos néz e hív.

No finlandês, os paradigmas verbais em que a raiz é realizada em apenas uma sílaba são unicamente harmônicos. Se se examina o paradigma flexional de verbos como mennä 'ir' (no final do apêndice) com atenção, constata-se que ele todo contém sufixos flexionais com vogais anteriores. Mais especificamente, há nele 13 formas com sufixos alternantes não-arredondados e somente $4 \mathrm{com}$ sufixos alternantes arredondados: os particípios mennyt e menty, além das terceiras pessoas do imperativo, menköön (singular) e menkööt (plural). Essas formas, diferentemente do que ocorre com elo, não apresentam preferência por ocorrerem com vogais posteriores. O crucial é que são apenas essas quatro formas com sufixos arredondados em todo o paradigma verbal. Se compararmos os paradigmas flexionais de lähtö e elo, vistos no apêndice, nestes a vogal arredondada ocorre no paradigma inteiro. Interpreta-se essa situação como resultante de um conflito entre uniformidade paradigmática e a evitação de vogais anteriores arredondadas.

A segunda diferença se verifica nos paradigmas derivacionais ou paradigmas estendidos. ${ }^{17}$ Examinando inicialmente o húngaro, verifica-se que os paradigmas estendidos ou paradigmas derivacionais dos verbos néz e hív, vistos anteriormente, também apresentam vogais uniformemente harmônicas com a raiz ou uniformemente desarmônicas com a raiz.

16 Isso exclui os sufixos com vogais neutras, os quais não alternam. Vejam-se, por ex., o alativo -lle e o translativo -ksi do finlandès.

17 Apenas será esboçada uma explicação aqui, sem ser feita sua implementação pelos tableaux. 
27) VOGAIS HARMÔNICAS

néz 'olha'

nézés 'olhar, olhada'

nézet 'faz ver'

nézö 'espectador'
VOGAIS DESARMÔNICAS

hiv 'chama'

hivás 'chamado, chamamento'

hivat 'manda chamar'

hivó 'aquele que chama'

Tomem-se outras duas raízes, com as quais se pode ilustrar melhor a manutenção do mesmo tipo de vogal (unicamente harmônica ou unicamente desarmônica) nos paradigmas estendidos em húngaro:

28) VOGAIS HARMÔNICAS

ért 'entende'

értő́ 'entendedor'

értés 'entendimento'

érthet 'consegue entender'

értheto 'compreensível'

érthetetlen 'incompreensível'

érthetetlenség 'incompreensibilidade'

\author{
VOGAIS DESARMÔNICAS \\ bir 'possui, suporta' \\ biró 'possuidor, dotado (de)' \\ birás 'posse' \\ birhat 'consegue suportar' \\ bírható 'suportável'
}

birhatatlan 'insuportável'

birhatatlanság 'insuportabilidade'

Essa situação contrasta visivelmente com a do finlandês, no qual a mesma raiz produz alguns derivados com harmonia e outros com desarmonia vocálica. Exemplifica-se isso melhor a seguir.

29) DERIVADOS NÃO-UNIFORMES (Alguns harmônicos, outros desarmônicos) $)^{18}$

heikko 'fraco'

leipä 'pão'

$i k \ddot{a}$ 'idade'

heiketä 'enfraquecer (vi)'

leipoa 'fazer pão'

ikäinen 'de $\mathrm{x}$ anos'19

heikentää 'enfraquecer ( $\mathrm{vt})$ '

leipomo 'padaria'

ikuinen 'eterno'

heikontaa 'atenuar'

leipuri 'padeiro'

ikääntyä 'envelhecer'

heikontua 'atenuar-se'

leivos 'pastry'

18 Deve ser observado que sempre que ocorre essa situação em que alguns derivados são harmônicos e outros desarmônicos, ocorrem formas desamônicas apenas quando a vogal da primeira sílaba do sufixo é arredondada.

19 Ex. kolmeiküinen 'de 3 anos'. 
SOUZA, P. C. de. O finlandês e o hüngaro e a tipologia...

\section{Conclusão}

Comparando o funcionamento da desarmonia nas duas línguas que foram analisadas, verifica-se que no sistema fonológico do húngaro as raízes são consistentemente harmônicas ou consistentemente desarmônicas. Por outro lado, no sistema fonológico do finlandês, não é cada raiz mas cada lexema que é consistentemente harmônico ou consistentemente desarmônico.

Dito de outra forma, o húngaro apresenta concordância intraparadigmática e interparadigmática dos sufixos, embora nem sempre eles concordem com a raiz. Já o finlandês sempre apresenta concordância intraparadigmática, mas não interparadigmática dos sufixos.

Se se considerarem as razões da desarmonia vocálica, verifica-se que, em húngaro, ela é determinada pela necessidade de ausência de identidade, já que sempre encontra-se uma raiz específica coocorrendo com o mesmo subconjunto de alomorfes dos sufixos: sempre com alomorfes posteriores ou sempre com alomorfes anteriores, independentemente da possibilidade de gerar vogais marcadas com isso.

A desarmonia em finlandês, por sua vez, é determinada pela marcação (markedness-driven), já que a mesma raiz pode coocorrer num determinado paradigma flexional com sufixos anteriores e em outro paradigma flexional com sufixos posteriores.

Outra forma de caracterizar isso é constatar que o húngaro apresenta desarmonia mesmo em contextos em que não seria produzido um output com vogais marcadas, ao passo que a desarmonia em finlandês tem unicamente a finalidade de evitar um output com essas vogais.

Considerando as consequiências desses dois tipos de desarmonia em termos de suas implicações para a aquisição, pode-se ver que em finlandês a motivação fonológica da desarmonia é sempre visível. Talvez por isso possa haver discordância entre derivados diferentes de uma mesma raiz. Já em húngaro, como nem sempre a motivação fonológica é visível, ela é dependente da raiz; assim fica mais fácil adquirir a desarmonia se ela pelo menos for consistente para cada raiz.

Portanto, examinar os paradigmas de línguas com harmonia vocálica pode revelar características que até aqui não têm recebido o devido destaque na literatura fonológica. 
SOUZA, P. C. de. O finlandês e o húngaro e a tipologia...

\section{RESUMO}

O finlandês e o húngaro apresentam diversas propriedades em comum no funcionamento de sua harmonia vocálica. Ambos têm vogais neutras, as quais são foneticamente anteriores e não-arredondadas. Essas vogais neutras são transparentes no sentido de que as vogais que as ladeiam concordam em seus traços, independentemente dos traços da vogal neutra. Outra característica comum é o fato de a harmonia ser determinada pelo radical, ou, dito de outra forma, o radical dominar os afixos (sufixos). Apesar de terem essas diversas características em comum, as duas línguas diferem acentuadamente no que se refere ao funcionamento paradigmático da harmonia vocálica, já que em húngaro as raízes são consistentemente harmônicas ou consistentemente desarmônicas. Já em finlandês, não é cada raiz mas cada lexema que é consistentemente harmônico ou consistentemente desarmônico. Quanto d̀ motivação da preferência pela desarmonia vocálica nessas línguas, ela é determinada morfologicamente em húngaro, ao passo que, em finlandês, ela é determinada fonologicamente, para evitar a ocorrência de vogais marcadas (anteriores arredondadas).

Palavras-chave: fonologia, finlandês, morfologia.

\section{ABSTRACT}

Finnish and Hungarian share a number of properties concerning their vowel harmony. Both have neutral vowels, which are phonetically front and unrounded. These neutral vowels are transparent in the sense that the vowels located in adjacent syllables have to agree in their features, irrespective of the features of the neutral vowel. Another common characteristic is that both languages have stem-controlled harmony, that is, the feature specifications of the stem dominate those of the affixes (suffixes). Although they have these characteristics in common, both languages differ markedly in the paradigmatic side of vowel harmony, since in Hungarian roots are consistently harmonic or consistently disharmonic. In Finnish, on the other hand, it is not the roots, but the lexemes, which are consistently harmonic or consistently disharmonic. As for the motivation for the preference of vowel disharmony in these languages, it is morphologically driven in Hungarian but phonologically driven in Finnish, occurring in the latter in order to avoid marked (front round) vowels.

Key-words: phonology, Finnish, morphology. 
SOUZA, P. C. de. O finlandês e o húngaro e a tipologia...

\section{REFERÊNCIAS}

ARCHANGELI, Diana; PULLEYBLANK, Douglas. Grounded phonology. Cambridge, MA: MIT Press, 1994.

BÁNHIDI, Zoltán; JÓKAY, Zoltán; SZABÓ, Dénes. Learn Hungarian. Budapest: Kultúra, 1965.

BAKOVI, Eric. Harmony, dominance and control. Brunswick, 2000. PhD. Dissertation University of New Jersey.

BENUA, Laura. Transderivational identity: phonological relations between words. Amherst, 1997. Tese (Doutorado) - University of Massachusetts.

BISOL, Leda. Harmonização vocálica. Rio de Janeiro, 1981. Tese (Doutorado) - Universidade Federal do Rio de Janeiro.

BISOL, Leda. Harmonização vocálica, uma regra variável. Tempo Brasileiro, n. 78/79, p. 73-96, 1984.

BISOL, Leda. A harmonização vocálica na fala culta (dados do projeto NURC). DELTA, v. 4, p. 1-20, 1988.

BURZIO, Luigi. Multiple correspondence. Lingua, v. 104, p. 79-109, 1998.

CHAGAS DE SOUZA, Paulo. Harmonia vocálica, contrastividade e licenciamento em finlandês. In: ENCONTRO NACIONAL DA ANPOLL, 17., 2002, Gramado. Anais... Porto Alegre: UFRGS, 2002a.

CHAGAS DE SOUZA, Paulo. Harmonia vocálica, marcação e correspondência em finlandês. In: SEMINÁRIO INTERNACIONAL DE FONOLOGIA, 2., 2002, Porto Alegre. Anais... Porto Alegre: PUC-RS, 2002b.

CLEMENTS, G. N.; HUME, Elizabeth V. The internal organization of speech sounds. In: GOLDSMITH, John A. (Org.). The handbook of phonological theory. Oxford: Blackwell, 1995. p. 245-306.

GOLDSMITH, John. Vowel harmony in Khalkha Mongolian, Yaka, Finnish, and Hungarian. Phonology, v. 2, p. 253-275, 1985.

HARRIS, J. Evidence from Portuguese for the elsewhere condition in phonology. Linguistic Inquiry, v. 8, p. 611-625, 1974.

KIPARSKY, Paul; PAJUSALU, Karl. Towards a typology of disharmony. Disponivel em: <http://www.stanford.edw/kiparsky> Acesso em: 2003.

KRÄMER, Martin. Vowel harmony and correspondence theory. Düsseldorf, 2001. Tese (Doutorado) - Heinrich Heine Universität.

MATEUS, M. H. M. Aspectos da fonologia portuguesa. Lisboa: Centro de Estudos Filológicos, 1975. 
SOUZA, P. C. de. O finlandês e o húngaro e a tipologia...

MCCARTHY, John. A thematic guide to optimality theory. Cambridge: Cambridge University Press, 2002.

MCCARTHY, John. Optimal paradigms. Disponível em <http://roa.rutgers.edu. ROA-485> Acesso em: 2002.

NASCIMENTO, Thiago Humberto do. Harmonia vocálica em finlandês. In: SIICUSP, 11., 2003.

QUICOLI, A. Carlos. Harmony, lowering and nasalization in Brazilian Portuguese. Lingua, v. 80 , p. $295-331,1990$.

SMOLENSKY, Paul. Harmony, markedness, and phonological activity. In: RUTGERS OPTIMALITY WORKSHOP, 1993. Rutgers University. Disponível em: <http:// roa.rutgers.edu.ROA-87>

WETZELS, Leo. Harmonização vocálica, truncamento, abaixamento e neutralização no sistema verbal do português: uma análise autossegmental. Cadernos de Estudos Lingüisticos, v. 21 , p. $25-58,1991$.

VAN DER HULST, Harry; VAN DER WEIJER, Jeroen. Vowel harmony. In: GOLDSMITH, John A. (Org.). The handbook of phonological theory. Oxford: Blackwell, 1995. p. 495-534. 
SOUZA, P. C. de. O finlandês e o húngaro e a tipologia...

\section{APÊNDICE}

TABELA 1 - DECLINAÇĀO DOS SUBSTANTIVOS RÉSZ 'PARTE' E HÍD 'PONTE' EM HÚNGARO

\begin{tabular}{|c|c|c|c|c|}
\hline & \multicolumn{2}{|c|}{ RÉSZ (harmónico) } & \multicolumn{2}{|c|}{ HíD (desarmônico) } \\
\hline & SINGULAR & PLURAL & SINGULAR & PLURAL \\
\hline nominativo & rész & részek & hid & hildak \\
\hline acusativo & részt & részekct & hidat & hidakat \\
\hline gen/dat. & résznck & részeknek & hídnak & hidaknak \\
\hline clativo & részzbōl & részekbő! & hídból & hldakból \\
\hline Inessivo & részben & részekben & hídban & hldakban \\
\hline inativo & részbe & részekbe & hidba & hidakba \\
\hline ablativo & résztol & részektôl & hídtol & hidaktoll \\
\hline adessivo & résznćl & részcknél & hidnal & hidaknál \\
\hline alativo & részhez & részekbez & hIdhoz & bidakhoz \\
\hline sublatlvo & részze & részekre & hidra & hidakra \\
\hline superessivo & részen & részeken & hidon & hidakon \\
\hline delativo & részrōl & részekröl & hídról & hidakról \\
\hline translativo & résszé & részckké & hiddd & hidakkd \\
\hline comitativo & rósszel & részekkel & hiddal & hidakkal \\
\hline
\end{tabular}

TABELA 2 - DECLINAÇÃO DOS SUBSTANTIVOS LÄHTÖ 'PARTIDA, SAÍDA' E ELO 'VIDA' EM FINLANDÊS

\begin{tabular}{|c|c|c|c|c|}
\hline & \multicolumn{2}{|c|}{ LÄHTO (harmónico) } & \multicolumn{2}{|c|}{ ELO (desarmônico) } \\
\hline & SINGULAR & PLURAL & SINGULAR & PLURAL \\
\hline nominativo & Iähtö & lähdöt & clo & elot \\
\hline genitivo & Iähdōn & Iähtöjen & clon & elojen \\
\hline partltivo & Iähtö̃ & lähtăjă & cloa & eloja \\
\hline clativo & lähdöstä & lähdöistã & closta & eloista \\
\hline Incssivo & lähdōssä & Iăhdölssä & clossa & clolssa \\
\hline ilativo & lähtōôn & lähtöihin & eloon & eloihin \\
\hline ablativo & Iähdōltă & lähdöilttä & clolta & cloilta \\
\hline adessivo & Jāhdōllä & lähdölllä & elolla & eloilla \\
\hline alativo & lähdölle & lähdöllle & elolle & eloille \\
\hline translativo & Iähdöksl & lähdölksı & eloksi & eloiks! \\
\hline essivo & lāhtōnā & lähtölna & clona & cloina \\
\hline
\end{tabular}


SOUZA. P. C. de. O finlandês e o húngaro e a tipologia...

TABELA 3 - FORMAS SIMPLES DOS VERBOS NÉZ 'OLHAR' E HIV 'CHAMAR' NO INDICATIVO EM HÜNGARO

\begin{tabular}{|c|c|c|c|c|}
\hline & \multicolumn{2}{|c|}{ Indefinido } & \multicolumn{2}{|c|}{ IndennIdo } \\
\hline & presente & pansedo & presente & passado \\
\hline I"pcse 28 & nezek & neztem & hivok & hivtam \\
\hline $2^{\circ}$ pess $2 x$ & nezel & $n \in z+d]$ & hivex & hivth \\
\hline $3^{2}$ pens sp & nta & nezett & hiv & hivort \\
\hline$I^{*}$ pess pl & nEzUnk & ntztank & hivunk & hiviunk \\
\hline 2* prsx pl $^{*}$ & neztek & nEztetek & hivtok & hivtotok \\
\hline \multirow[t]{3}{*}{$3^{*}$ pess pl } & ntznck & ndatek & hivnak & hivtak \\
\hline & \multicolumn{2}{|c|}{ deñido } & \multicolumn{2}{|c|}{ definido } \\
\hline & presente & pensado & preserinte & passedo \\
\hline 1 pess 48 & nézem & nextem & hivom & Divtem \\
\hline $2^{-}$pess sq & nized & nexted & hivod & Alvted \\
\hline 30 pess un & $n \in \dot{x i}$ & mezte & hivjn & hivte \\
\hline I* pess pl & nezzak & ntztak & hivjuk & hivtuk \\
\hline $2^{-}$pess pl & nezdick & neztetek & Aivjdtok & hividiok \\
\hline $3^{*}$ pess p! & nexjk & nextek & hivjak & hivtak \\
\hline
\end{tabular}

- FORMAS SIMPLES DO VERBO MENNÄ 'ir'

INDICATIVO

PRESENTE ATIVO

IMPERFEITO ATIVO

menen

menin

menet

menit

menee

meni

menemme

menimme

menette

menitte

menevät

menivät

PRESENTE PASSIVO

IMPERFEITO PASSIVO

mennään

mentiin

ACT. PRES. CONDITIONAL ACT. PRESENT POTENTIAL

menisin

mennen

menisit

mennet

menisi

mennee

menisimme

mennemme

menisitte

mennette

menisivät

mennevät 
PASS. PRES. CONDITIONAL PASS. PRESENT POTENTIAL

mentäisiin

ACT. PRES. IMPERATIVE

mene

menköön

menkäämme

menkää

menkööt

INFINITIVE

mennä

I PARTICIPLE

ACTIVE

PASSIVE mentäneen

PASSIVE

mentäköön

\begin{tabular}{lll} 
& \multicolumn{1}{c}{ I PARTICIPLE } \\
menevä & ACTIVE & mennyt \\
mentävä & PASSIVE & menty
\end{tabular}

